\title{
Interactive comment on "An Explicit GIS-Based River Basin Framework for Aquatic Ecosystem Conservation in the Amazon" by Eduardo Venticinque et al.
}

\author{
A. Schäfer (Referee) \\ angela.schaefer@awi.de \\ Received and published: 14 September 2016
}

The effort to develop and share the presented GIS data with the wider community is very commendable. It will foster reuse and further elaboration for analysis, management and monitoring of the aquatic Amazon basin systems in the future.

Since I already started working on the first version of manuscript I switch over to the new revised manuscript to avoid duplication. So I observed that the first reviewers comments were considered thoroughly and most of my intended comments are now already resolved in the revised manuscript. Now the manuscript is written well and comprehensible. 
But there are two general aspects concerning the reusability of the published data sets in the long run and the lacking description of methods that the applied software tools are based on which have been used to produce the data products.

General comments:

One important issue is concerning the proprietary geodatabase format of ESRI that the data are stored in and published. (Or did I miss another download Option at KNB?) Not every researcher or public authority who wants to reuse the data is familiar with or can afford the ESRI GIS software. Therefore, I would suggest to store and publish all data additionally in a standard shapefile format, that is independent of proprietary software or software version to be handled with.

In chapter 5.3 the authors cite the application of special ESRI tools to produce the resulting data products, e.g. Spatial Analyst Extension tool "Flow Direction", "Flow Accumulation", "Stream Definition", "Stream Order". Generally, I think it is not acceptable just to point out the name and the application of a specific software tool as such as a sufficient reference to the method of how a data set has been produced. Anyhow ready-to-use software tools evolve, disappear or cannot be applied any more over time. Therefore I suggest to summarize each implied method that the ESRI software tools are based on independently and comprehensibly. So that the production of each data set can be understood and clearly reproduced by other software applications as long as the method, algorithms, assumptions, parameter settings and constraints are sufficiently described. Of course this implies a proper citation of the original references of the methods that were combined and applied by the handy-to-use ESRI software tools. Maybe there are published ESRI manuals that can be cited for this reason. In chapter 5.4 the same is true for the "watershed delineation" tool of ArcHydro 2.0, the "catchment grid delineation" and the "catchment polygon processing" tool ... and any other software tools used to create the published data sets.

Interactive

comment

Specific comments:

Printer-friendly version

Discussion paper 
L151: I am aware of the limitation of free storage place at KNB, but it would be very good for a future holistic research approach for the whole user community, to find a way to publish or make available your underlying mosaicked and uniformed DEM as well. There are additional repositories for publishing large data sets. Have there been any edge matching problems while mosaicking or significant alteration to the original CGIAR-CSI 4.1 DEM?

Interactive

L196: check "1st to 3nd order streams..."

L206-207: "The length ... was also determined with ArcGIS 10.1 in ... projection" This is not a proper description of a method. Are there special software dependent spatial operations or parameter settings in this context that need to be described to the prospective data user so that the data set could be reused or reproduced by other GIS software or versions in the future?

L210-211: the sentence is not properly finished and check "... Level1 to Level7"

L262: Could you provide (publish) the final wetland mask along with the other data sets? It might be very useful for further questions.

L280-282: Could you describe the source and application of the regional knowledge and your method of visual analysis of optical imagery through Google Earth to distinguish different river types by color a bit more detailed?

L287: Could you give references or sources of the phenomenon that characiform fish species spawn at confluences of different types of rivers?

Figure 1: check again "of the first four levels ..."

Data set "NodesGeneral" and "Nodes_MainStemFischRegion": please give reason in the text for distinction of small and big order of tributaries in confluence as described in the attributes of these data sets.

Interactive comment on Earth Syst. Sci. Data Discuss., doi:10.5194/essd-2016-17, 2016. 